\title{
Leading with digital in an age of supercomplexity
}

\author{
Lawrie Phipps ${ }^{* a}$, Donna Lanclos ${ }^{\mathrm{b}}$ \\ a. Jisc \\ b. J Murrey Atkins Library, UNC Charlotte
}

(Received August 2017; final version received October 2017)

\section{Abstract}

Across education all aspects of practice, including teaching, research, public engagement and administration, are taking place increasingly against a digital backdrop. As digital becomes widely recognised as both a key element of enabling institutional change, and creating challenges for all institutional activities, Jisc have developed a digital leaders course to engage delegates with their own digital practices, and help them in applying tools and methods to both support their own development and leverage digital in their organisation. This concise practice report reflects on the initial courses,some of the delegate reactions and drivers to participate in the course. It also outlines the structure of the course and the underpinning approaches taken. The intent here is to take the observations we have made over two years delivering five iterations of this course, and suggest positive directions forward for those interested in researching and developing effective leadership strategies around digital environments in higher and further education. Barnett's definition of supercomplexity, a time of uncertainty, unpredictability, challenge and change frames the nature of the education landscape faced by institutions well. Through the digital leaders course, Jisc seeks to both frame the challenges created by digital, and also show digital as providing the capacity and capabilities to respond to supercomplexity.

\section{Introduction}

Jisc is a not-for profit provider of services to United Kingdom higher and further education institutions and funded largely by higher and further education governmental funding bodies. Since October 2015 Jisc has been running the Digital Leaders Course for Higher and Further Education. The course builds on some of the approaches and research from the Changing Learning Landscape programme (LFHE, 2014). Whereas some approaches to developing digital skills have relied heavily on diagnostic testing and focused on recipes and checklists for enhancing capabilities, the purpose of the Jisc leaders course was to enable delegates to investigate and develop the roots of their own digital practice and that of their organisation; setting their own priorities for development in the context of their role. In running and further developing the course, further information has been garnered from the participants, via follow-up visits, structured interviews, and institutional feedback forms, to identify effective

*Corresponding author. Email: Lawrie.Phipps@jisc.ac.uk

Irish Journal of Technology Enhanced Learning Ireland, 2017. @ 2017 L Phipps and D Lanclos. The Irish Journal of Technology Enhanced Learning Ireland is the journal of the Irish Learning Technology Association, an Irish-based professional and scholarly society and membership organisation. (CRO\# 520231) http://www.ilta.ie/. This is an Open Access article distributed under the terms of the Creative Commons Attribution 4.0 International License (http://creativecommons.org/licenses/by/4.0), allowing third parties to copy and redistribute the material in any medium or format and to remix, transform, and build upon the material for any purpose, even commercially, provided the original work is properly cited and states its license. 
approaches and early successes in both the delegates' digital capability and in changemanagement approaches involving digital ${ }^{1}$.

In this article, we look at the framing of the course, and the discussions from leaders that have emerged from their participation in it, so as to point to directions we hope the higher and further education sector will take in developing and researching effective leadership practices in digital environments. In particular we are interested in the ways that the conversations emerging from several runs of the leadership course are pointing us towards the need for more attention to and development of organisational culture, rather than exclusive attention to digital tools and skills. Here we describe the framing and intentions of the course, contextualise it, and draw out themes that we hope can be explored further via research and additional development around digital strategy and policy.

The approach of the Jisc Digital Leaders course is designed to provide staff in institutions with an awareness, and ability to respond both to and with digital in a time of 'Supercomplexity', the shorthand term used by Barnett (2000) to describe the state of affairs in which we find ourselves: one of uncertainty, unpredictability, challenge and change.

The core work of educational organisations - teaching and learning, research and innovation, partnership-building, public communication and organisational management - takes place in an increasingly digital setting (Evans \& Morris, 2016; Pearce et al, 2010). In developing the Jisc Digital Leaders course it was recognised that leaders in education need to both be effective in their own use of digital and understand the benefits and affordances of digital in leading organisations and departments. Furthermore, strong "digital leadership" will be a key feature of effective educational organisations, and its lack can be a significant barrier to progress. Technology in universities is no longer the sole domain of IT managers, or indeed those staff involved in Technology Enhanced Learning (TEL). The opportunities and risks offered by developments in digital technology need to inform the full range of institutional strategies and be embedded into the institution's core mission.

\section{Identifying Wants, Fulfilling Needs}

The Jisc Digital Leaders course began as a pilot project in october 2015. We ran two different four-day courses, one for further education and skills leaders and one for higher education leaders, recruited from across the UK and Ireland. Since then two further versions of the residential course, and two non-residential single institution courses have been run. As a result of feedback we no longer have separate runs for further and higher education, as we realised that the content of the conversations around the role of digital in higher and further education were broadly similar, and people from all parts of the sector learned a great deal from their colleagues in different areas. To date, 145 people have gone through the residential course, with courses booked for November 2017 and Spring 2018.

All leadership roles in institutions need to have some understanding of the affordances and challenges associated with digital and leaders need to feel confident in their own digital capabilities and able to model at least some of the digital behaviours they want their staff to

\footnotetext{
${ }^{1}$ During the course Jisc asks for consent of participants to use the materials generated within the course for analysis, reporting, and iterations of future versions of the course. Each course is evaluated and Jisc also seeks to interview delegates to elicit further feedback. All material, including feedback and evaluation is anonymised. 2
} 
display. They need a vision for digital technology in their part of the organisation and confidence to trust other people who have the technical and specialised expertise to implement the vision. In addition, and especially in the later courses, the diversity of roles participating in the course has increased. As well as academic leaders, participants have included staff from Information and Technology Services, Libraries, Human Resources, Communications and Marketing, Estates and Academic Support Staff (Staff and Educational Developers, TEL Staff).

In each run of the course, there were individuals who wanted top tips, and tool recommendations. Our intention was not, and never has been to fill this desire. There will never be a tool that will help address uncertainty, unpredictability, challenge and change. Several attendees had been sent to the course because they had been tasked with writing a "digital strategy," but what we needed to do at the outset of the course was to get them thinking about what comes before that.

Running the course is an exercise in facilitating conversations grounded in initial activities that attempt to make the abstract a bit more concrete. We use (as many workshop facilitators do) sticky notes, colored markers, A4 paper, and the walls of the rooms we are in for recording, displaying, and collecting the perspectives in the room. For example, at the beginning of the most recent course, we collected what people's motivations were to come on the course. The motivations clustered into the following primary themes:

- Time

- Strategy

- Tools

- Networking

- Visualising and understanding practice

- Uncertainty, unpredictability, challenge and change

While "tools" is on their collective list of motivations, it stands out as being different from the other items, which are about process, organization, management, and people. We suspect that tools are on the list at least in part because the larger context in higher and further education highlights "skills" and "tools" as solutions to problems, as demonstrated, for example by Jenzabar (2016) and Educause (2017). This context frames our primary challenge in running a course like this: successfully encouraging delegates to move towards a set of motivations that is not about "tools". We designed the course to be a reflective space, from which strategic thinking can emerge. We recognise, through the structure of this course, the dearth of reflective time in our ordinary day jobs, and the importance of that time to build effective strategies. It is through fulfilling these non-tool-centred motivations that we can start to build the capacity and confidence for leaders to address supercomplexity.

\section{Structure of the course: Practice and Strategy}

The approach of the Jisc Digital Leadership Course is development rather than training, and it draws upon research that centers motivations to digital practice, in particular the Visitors and Residents approach to digital (White \& LeCornu, 2011; White \& LeCornu, 2017; Phipps, 2016; Lanclos, 2016; White, 2016) , contrasting with outmoded "Digital Native/Immigrants" 
notions (Margaryan et al, 2011; Prensky, 2001). The core of the first day is built around delegates mapping their practices. We therefore start with visualisation exercises, having the leaders draw, rather than write lists, as a way of moving them away from text-based notions of where they work and what they are trying to do.

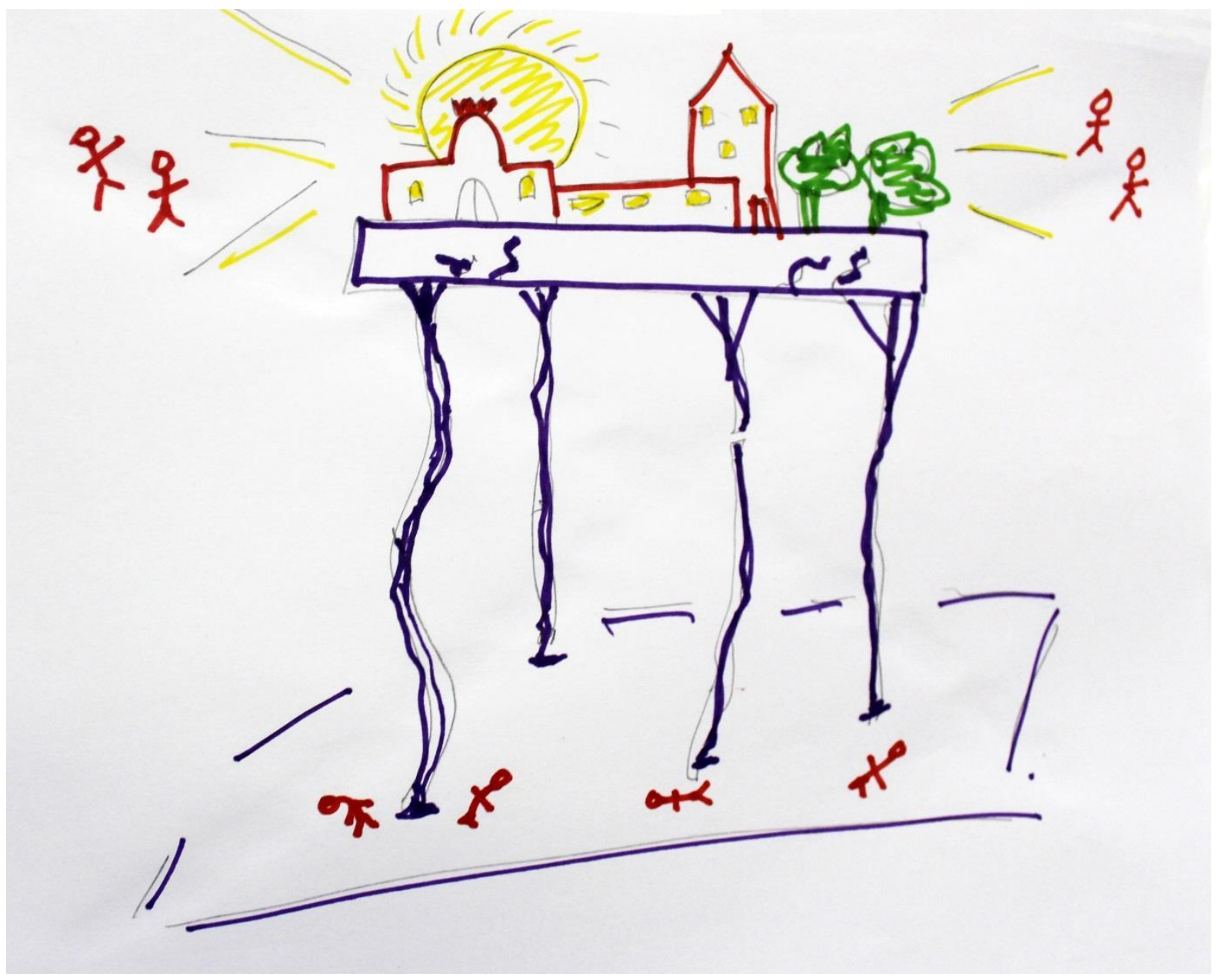

Figure 1: Institutional Representation

We asked delegates first to draw a representation of their own organisation. The picture in Figure 1 was drawn to illustrate the contrast between the image of the university, robust and full of happy people working and studying, with the precarious support structure (and the people victimised by that lack of support) that lies just underneath. 


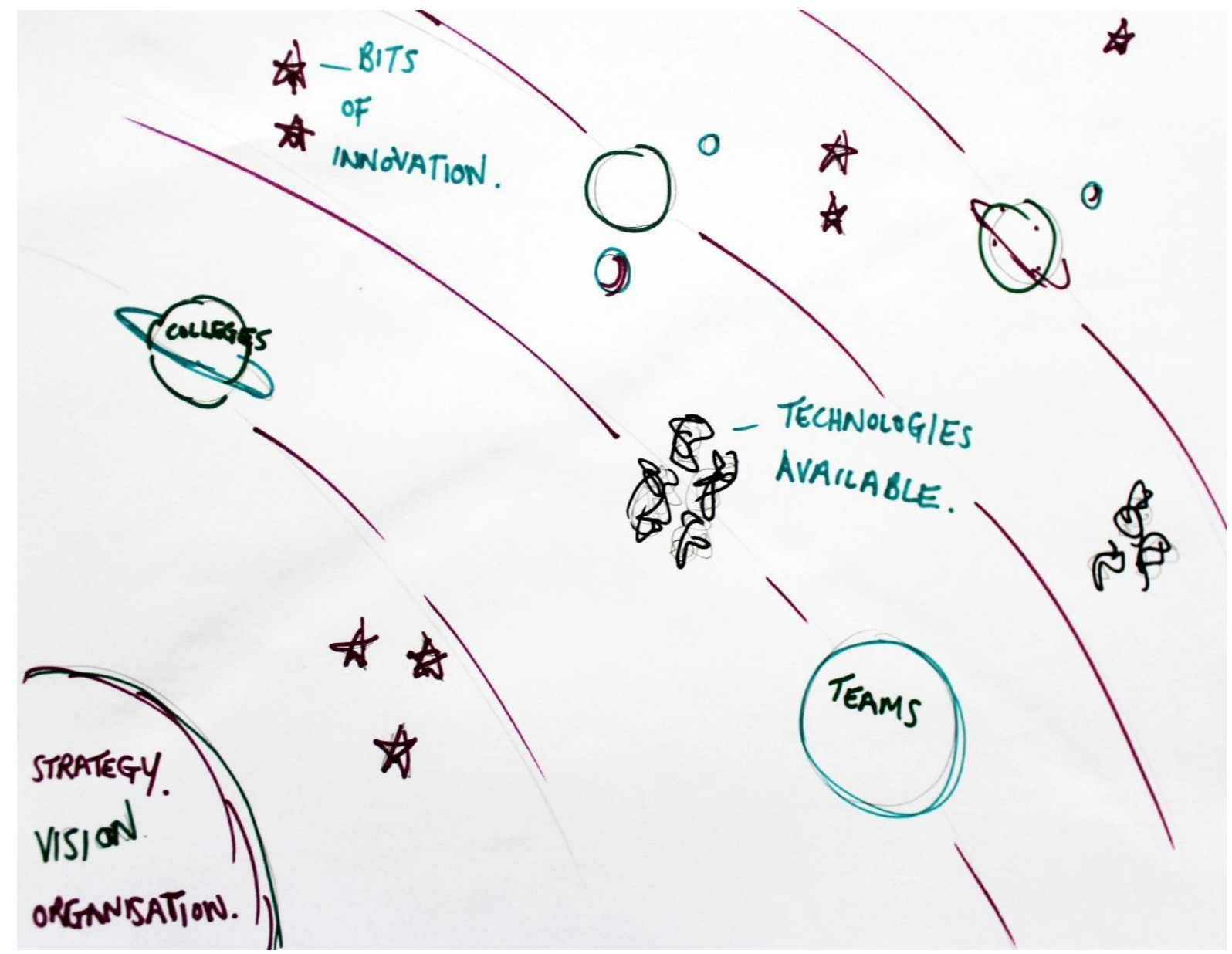

Figure 2: Institutional Representation (Value Alignment)

In Figure 2, a delegate represents their organisation as a system of planets, but ones that are not quite in alignment with the central values around which they orbit.

After they draw their organisations, and discuss these drawings with their fellow delegates, they are ready to move on to the visualisation of their personal digital practices. Using a pole graph, delegates engage with the Visitors and Residents framework, placing the digital things they do and places they visit on the graph, (see Figure 3) as a way of grounding their development in their own practices. 


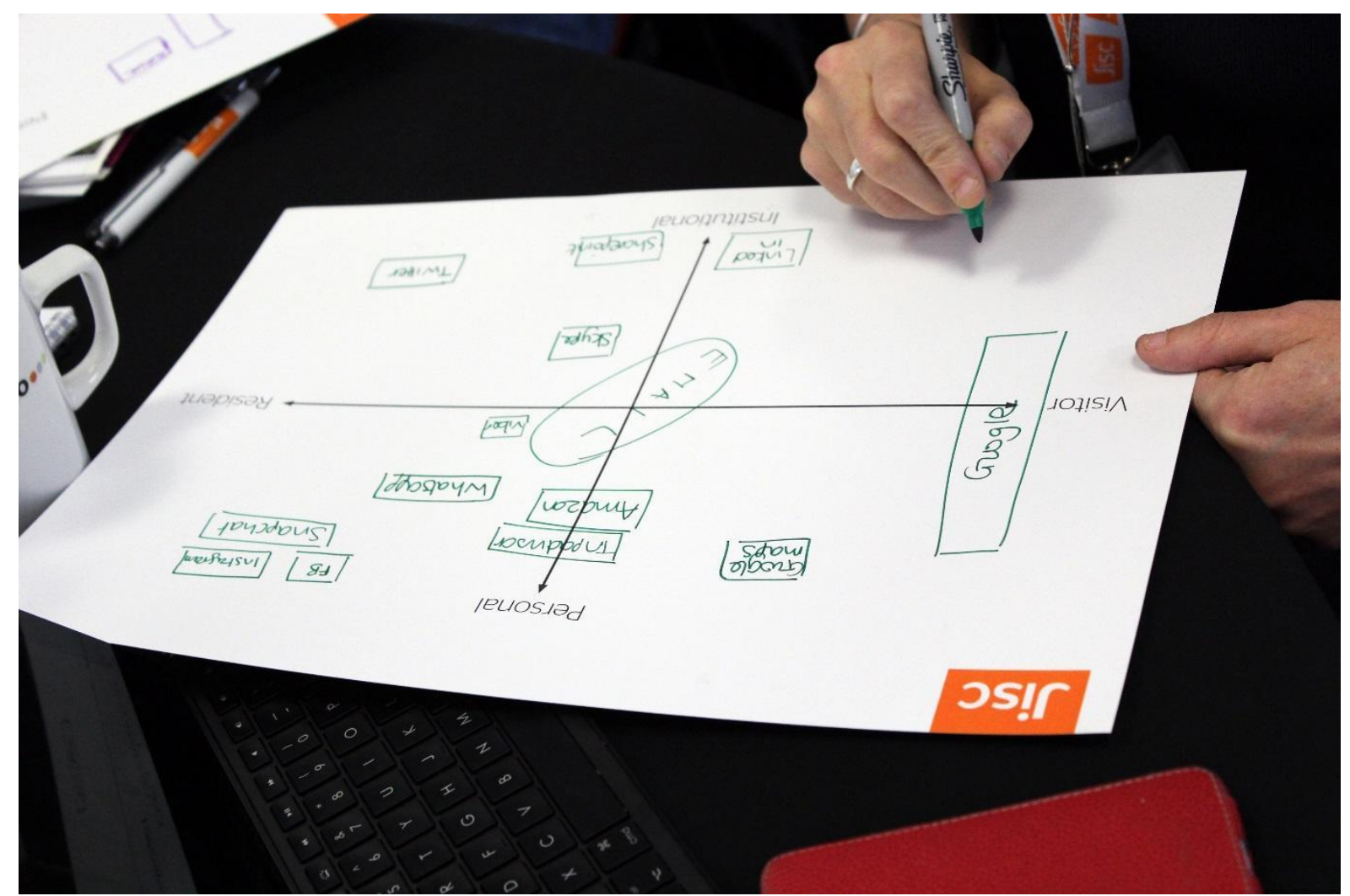

Figure 3: Mapping along a pole graph

In these mapping exercises one of the fundamental shifts we are trying to facilitate is in moving from thinking about digital as a tool or a set of resources, what we call "visitor" mode, towards considering digital as a place, what we call "resident" mode, where people can engage with other people, have conversations, and exchange ideas. Delegates are encouraged to annotate their practice maps, for example, with the ways they would like to move their practice (e.g., accelerating, enhancing, or decreasing particular practices), or signaling the ways that their practices are linked, or informed by other priorities.

In mapping what they do as individuals, the leaders are then primed to move to strategic approaches to their organisation's digital footprint. In this case, as with the individual mapping, the process of creating a map of practice allows for reflection, not decisions about what is right and what is wrong. The intention is to provide spaces where choices can be better understood. The process of developing their own map allows leaders to think about maps for their organisation and how the organisation engages with its community. 


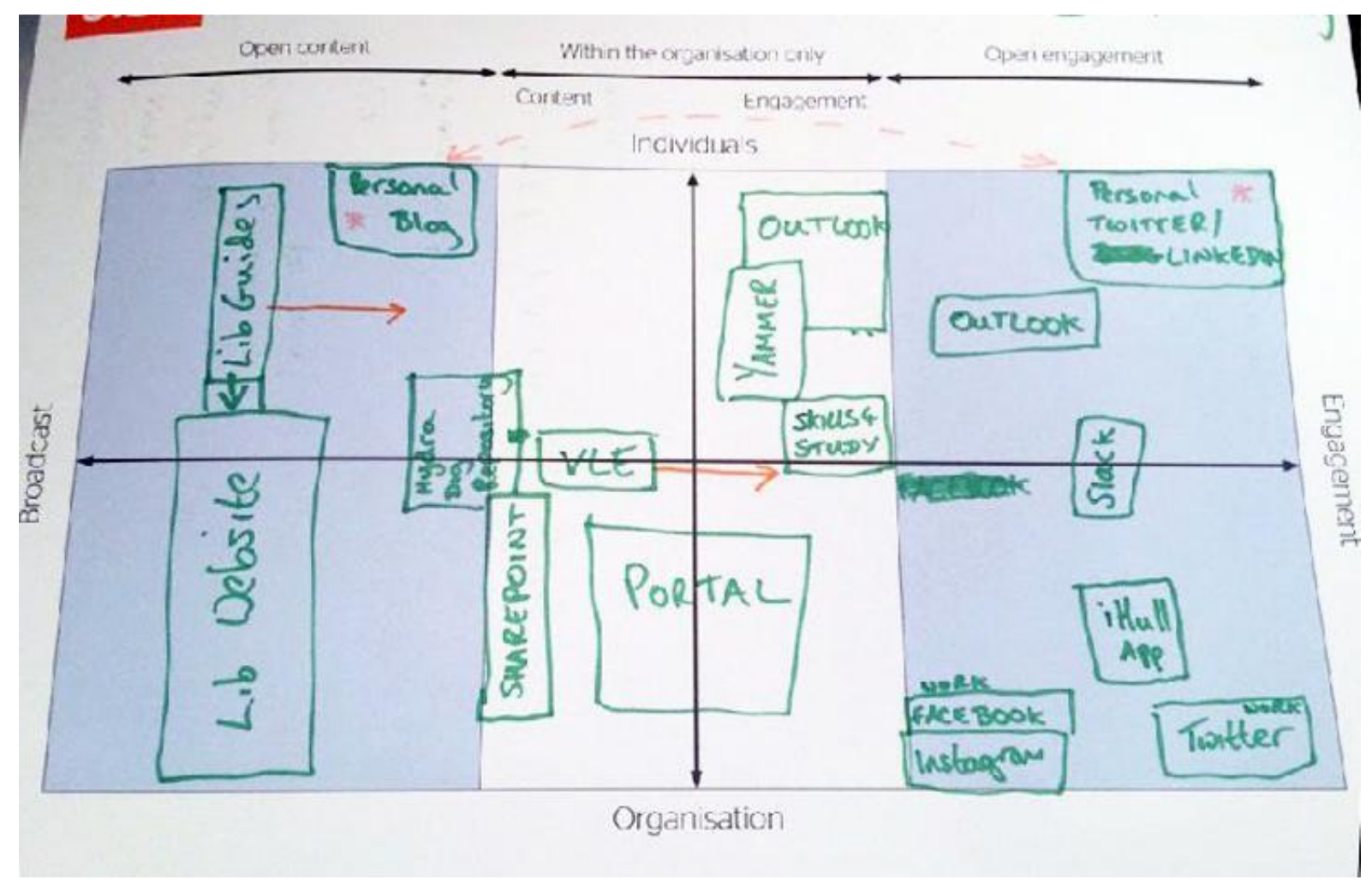

Figure 4: Organisational Map

The organisational map in Figure 4 is an early iteration of the mapping process, where we tried to get delegates to simultaneously map the range of practice (and the motivations behind those practices) as well as whether those practices were open (accessible on the wider web) or closed (locked behind a password). In future versions of the course, we are moving to the simpler mapping process (Figure 5), and will be discussing the open/closed spectrum (and the motivations behind that) as a separate stage of the mapping. In Figure 4, the arrows indicate where this individual wished their organisational practices could be located, overall hoping for more engagement, and less broadcast. 


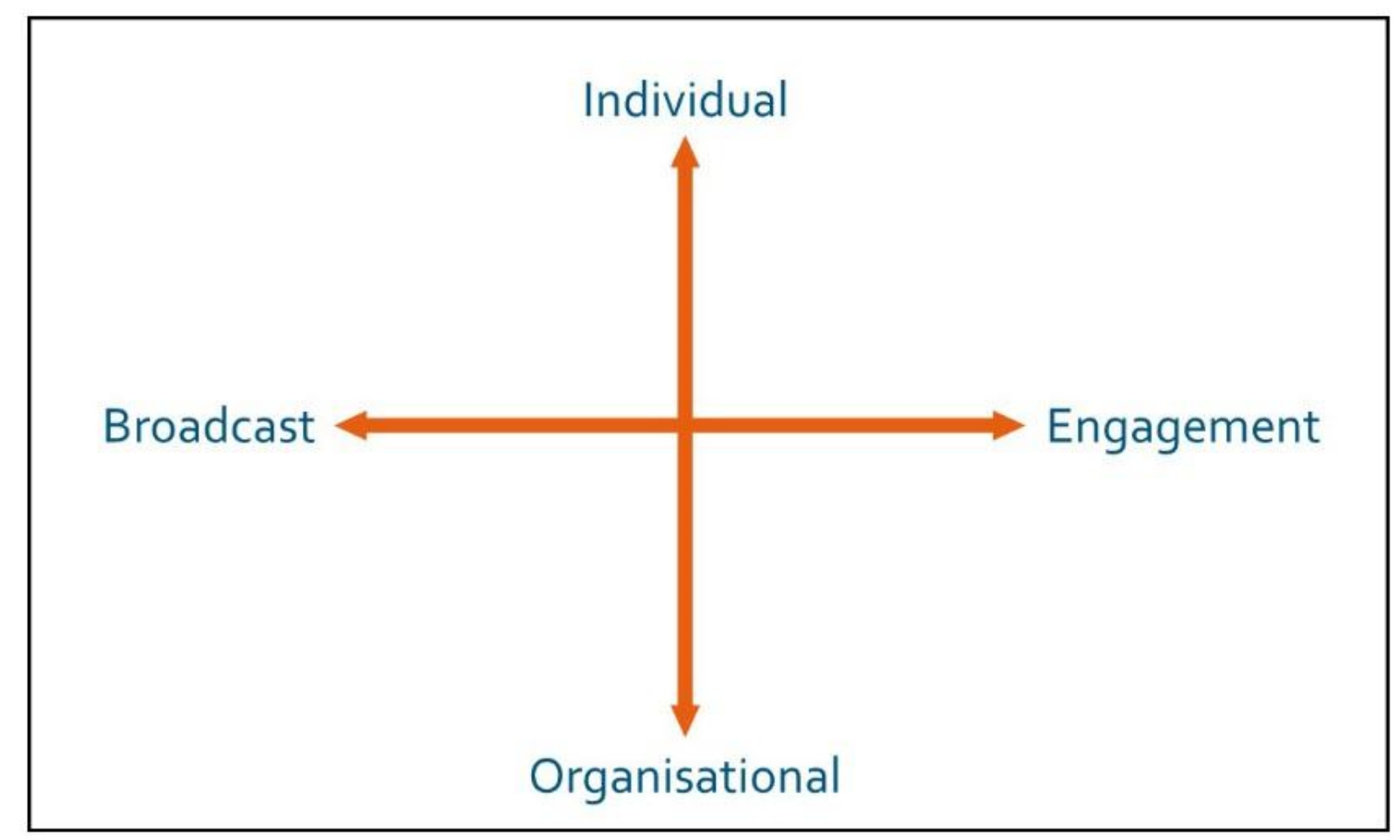

Figure 5: Simpler Map for Organisational Mapping

In both the new and old organisational templates, delegates are encouraged to think about the entirety of their organisation's digital practices as best they can recall them--part of the challenge is that of course no one individual has a comprehensive perspective on all of the digital places, tools, and activities in a given institution. One result is usually that people start to have ideas about who else they need to talk to, to get a more holistic perspective. The distinction between "broadcast" of information and "engagement" with people is derived from that which we make between visitor and resident in the individual maps, again drawing out the fundamental difference between an operational approach to digital, and one that sees the human potential for interaction and engagement via digital places.

The maps that delegates produce always reflect a range of practices, something that occurs in Visitors and Residents mapping workshops in other contexts, such as libraries, and teaching and learning (White, 2016a). We encounter, in the Jisc course, leaders who are very practiced and confident in digital places, and others who are confidently disconnected from digital, for very specific reasons around time, privacy, and professionalism. Participants produce maps of organisations that are operating predominantly in broadcast mode, and others that have both broadcast and engagement as part of their digital presence. None of the mapping is intended to make people think there is a right way to "do digital." Part of the point is, regardless of one's own personal approach, leaders need to be aware of the range of possibilities in digital places and practices.

The important aim in all of the mapping exercises we run participants through during the Jisc Leaders Course is not the representation that each delegate produces, but is a shift in thinking. In each case, both individual and organisational mapping, there are no templates in this approach that can be elicited, no best practice that can be duplicated. The process is a 
journey, and the maps that leaders create are merely a snapshot of where their current practice stands. The Jisc Leaders Course uses digital practice maps created as a development tool, allowing delegates to understand and reflect, with their peers, on what they do, and importantly what their motivations and aspirations are. These moments of understanding and reflection are the real outcomes of this process, which in turn have already led to changes within participant organisations. Swansea University staff participated in the course and used the techniques to refocus their strategy around active learning classrooms (Griffith, 2017). Cardiff University staff used the course as a springboard to accelerate their deployment of digital capabilities frameworks both in the UK and in overseas campuses (Parry, 2017).

\section{Discussion and Conclusions}

During the discussion of the results of the mapping exercises, change management approaches emerge, with delegates looking at how they approach digital change projects and what makes them successful (or not). We have, in the process of running the Jisc Leaders' Course, been particularly struck by the ways that even conversations that start grounded in lists of tools and skills swiftly develop into discussions of organisational culture and practice, history, and the occasionally difficult process of working with people. We would like to use the insights highlighted in this paper to encourage our colleagues in the sector to reflect on the ways in which digital is approached at both a personal and strategic level, identifying the drivers and the needs that they think they can respond to and fulfill via digital. Through working with leaders in higher and further education it is apparent that many of the technology related adoption issues can be attributed to people lacking 'confidence' in their digital skills or, instances where organisational culture is engaged in digital rhetoric rather than the work of transforming digital behaviour.

The role of effective leadership in institutions must now include how leaders see and use digital; both in terms of how new digital practices are emerging and using digital to respond to change. In developing an approach on the Jisc Digital Leaders course we seek to give leaders a place, to situate themselves within their own digital practices and then develop outward, encompassing opportunities to incorporate digital in their practice and leveraging digital for the benefit of their organisational goals. Our role is not to give them skills and competencies (because they already have those), but to inspire them to reflect on, develop, and grow their digital confidence.

Leading organisations in a time of supercomplexity is inevitably difficult, the digital layer should not be seen as another "challenge" to be overcome, but should be embraced as an opportunity. "Digital" permeates every part of an institution, and strategy around digital cannot be limited to just one piece of any organisation. Digital tools, places, and practices also provide ways for individuals and institutions to respond and thrive in new realities.

The context in which educational practices take place is changing; quality metrics, student funding, policy imperatives and the rise of new providers seeking to compete with traditional providers all have an impact. Barnett's reference to supercomplexity is prescient but should not come as a surprise as, especially in higher education, change can be seen as the norm. The myriad drivers for change in institutions may be ephemeral, or more sustained, and in order to better respond all staff, including academics, need to be able to understand the 
change processes and adapt their practices accordingly. Digital is a facet of supercomplexity, an indelible part of the context in which changes are occurring.

\section{References}

Barnett, R. (2000) Realizing the university in an age of supercomplexity. Maidenhead, UK: McGraw-Hill/Open University

Educause (2017) Higher Education's Top 10 Strategic Technologies for 2017 (2017, January 17) Retrieved from https://library.educause.edu/resources/2017/1/higher-educations-top-10strategic-technologies-for-2017

Evans, L and Morris, N (2016) Leading Technology-Enhanced Learning in Higher Education. Research and Development Series, Leadership Foundation for Higher Education

Jenzabar (2016) Solving Higher Ed's Biggest Problems with Technology (2017, October 27) retrieved from https://www.jenzabar.com/blog/2016/10/27/solving-higher-eds-biggestproblems-with-technology/

Richard Griffith [@ health_law] (11 October 2017) Active learning suite now up and running in the@SwanseaUni SHHS \#jiscdiglead@jamesclay @DonnaLanclos retrieved from https://twitter.com/health_law/status/918065134995681282

Lanclos, D. (2016, August 16) Ta Dah: A Hitchhiker's Guide to Doing a Visitors and Residents Workshop [blogpost] retrieved 23 August 2017

http://www.donnalanclos.com/ta-dah-the-hitchhikers-guide-to-doing-a-visitors-and-residentsworkshop/

Lanclos, D, Phipps, L, and White, D. (2016) Visitors and Residents: Mapping Your Digital Engagement. A set of mapping activities designed to facilitate reflection and discussion around online engagement. Retrieved 23/8/2017

https://docs.google.com/document/d/1Bpmv8CVX_q0r-

YEG4_zKUQLC12qmw6INWGtwfGaVM9g/edit\#

LFHE (2014) Changing the Learning Landscape Report, Retrieved from

https://www.lfhe.ac.uk/en/research-resources/resource-hub/cll/

Margaryan A, Littlejohn A, \& Vojt G. (2011). Are digital natives a myth or reality?

University students' use of digital technologies. Computers in Education. 56(2) (February

2011), 429-440. http://dx.doi.org/10.1016/j.compedu.2010.09.004

Parry, D (2017) ALTc Write-up (Day 2) [Blogpost] retrieved 20 October 2017

http://blogs.cardiff.ac.uk/learning-technology/2016/09/20/altc-write-up-day-2/

Pearce, N, Weller, M, Scanlon, E and Kinsley, S (2010). Digital scholarship considered: how new technologies could transform academic work. In Education, 16(1)

http://ineducation.ca/ineducation/article/view/44

Phipps, L. (2016) Mapping for Change [blogpost] retrieved 23 August 2016

http://lawriephipps.co.uk/?p=8305

Prensky, M, (2001) Digital natives, digital immigrants. On the Horizon, 9(1) Retrieved from http://www.marcprensky.com/writing/Prensky\%20-

\%20Digital\%20Natives, \%20Digital\%20Immigrants\%20-\%20Part1.pdf 
White, D. (2016, August 16) Visitors \& Residents - navigate the mapping

[blogpost] retrieved 23 August 2017 http://daveowhite.com/vandrworkshops/

White, D. (2016a, April 29) Truth and Method -- a review of Visitors and Residents [blogpost] retrieved 20 October 2017 http://daveowhite.com/truth-and-method/

White, D., \& Le Cornu, A. (2011). Visitors and Residents: A new typology for online engagement. First Monday, 16(9). doi:http://dx.doi.org/10.5210/fm.v16i9.3171

White, D., \& Le Cornu, A. (2017). Using 'Visitors and Residents' to visualise digital practices. First Monday, 22(8). doi:http://dx.doi.org/10.5210/fm.v22i8.7802 